\title{
Um triunfo de aprendizes: o som em O massacre da Serra Elétrica ${ }^{1}$
}

\author{
Rodrigo Carreiro' \\ I - UFPE
}

Recife (PE), Brasil

Resumo: Filme influente na consolidação de uma estética semidocumental muito popular no cinema de horror contemporâneo, O massacre da serra elétrica (The Texas chain saw massacre, Tobe Hooper, 1974) ganhou status de inovador, com o passar dos anos, por ter antecipado a explosão do subgênero slasher, e por causa da crueza das imagens. No entanto, pouco se fala do caráter arrojado dos sons que contribuem para assustar o público do filme. Este ensaio tem o objetivo de reconstituir o processo criativo da trilha sonora, destacando a presença majoritária de estudantes e aprendizes na equipe responsável pelo sound design, e enfatizando o modo pelo qual o relativo desconhecimento das práticas profissionais de pós-produção embaralhou as fronteiras entre música e efeitos sonoros, reforçando uma tendência estilística inovadora que influencia o cinema contemporâneo.

Palavras-Chave: análise fílmica; horror; sound design.

Abstract: A triumph of apprentices: sound in The Texas Chain Saw Massacre - An influential film in the consolidation of a very popular realistic semidocumentary aesthetics in contemporary horror films, The Texas Chain Saw Massacre (Tobe Hooper, 1974) has gained, over the years, innovative status for anticipating the boom of the slasher subgenre, and exploiting the rawness of its images. However, little is said of the bold nature of the sounds that contribute to frighten the audience. This essay aims to reconstruct the creative process of the soundtrack, highlighting the major presence of students and young aspiring professionals in the team responsible for the sound design, and emphasizing how the relative ignorance of professional post-production practices helped to scramble the boundaries between music and sound effects, thus reinforcing an innovative stylistic trend that influences contemporary cinema.

Keywords: film analysis; horror; sound design.

1 Uma versão preliminar deste artigo foi apresentada no $25^{\circ}$ Encontro Anual da Compós, realizado na Universidade Federal de Goiás (GO), em junho de 2016, dentro do GT Estudos de Som e Música. 


\section{Introdução}

Recife, 24 de outubro de 2014. A longa fila de cinéfilos em frente ao Cinema São Luiz, mais antiga sala de exibição da capital pernambucana, dá uma volta no quarteirão em frente ao Rio Capibaribe, cartão postal da cidade. Trata-se da noite de abertura da sétima edição da Janela Internacional do Cinema, festival que alterna sessões competitivas de filmes inéditos e exibições de clássicos. O programa da noite, que lotou os 992 assentos da sala, intriga uma parte dos presentes; afinal $O$ massacre da serra elétrica (The Texas chain saw massacre, Tobe Hooper, 1974), exibido em cópia restaurada no formato 4K, não costuma ser classificado como integrante do cânone de grandes obras de arte do cinema.

Não que haja dúvidas a respeito da importância do filme de estreia de Tobe Hooper. Produzido aos trancos e barrancos, em meio a um emaranhado de acordos jurídicos que oscilavam entre o ingênuo e o suspeito (para dizer o mínimo), O massacre da serra elétrica deixou um rastro de escândalo por onde foi exibido, foi objeto de proibição em países como a Inglaterra, e só alcançou o status de obra cult por causa da admiração sem reservas de um punhado de fanáticos - o tipo de público para o qual Jeffrey Sconce cunhou a definição de paracinema, definida como "uma contra-estética de sensibilidade subcultural dedicada a todos os tipos de detritos culturais [...] que deseja valorizar todas as formas de lixo cinematográfico - filmes que têm sido expressamente rejeitados, ou simplesmente ignorados, pela cultura cinematográfica legítima" (SCONCE, 1995, p. 372).

Embora seja um dos poucos títulos a marcar presença no acervo do prestigiado Museu de Arte Moderna de Nova York (EUA), O massacre da serra elétrica continua a ser recebido com alguma reserva por cinéfilos mais conservadores, para quem filmes de horror costumam fazer parte de uma espécie de segundo escalão do cânone cinematográfico. Daí o "pé atrás" de parte significativa do público recifense que lotava a sala. Foram precisos, contudo, poucos minutos de projeção para que os risos de escárnio desaparecessem, para dar lugar a uma visceral e coletiva experiência de horror cinematográfico. Comentários em blogs e redes sociais, publicados nos dias que se seguiram, trouxeram relatos como o texto a seguir, escrito por Júlio Pereira, estudante de Cinema da Universidade Federal de Pernambuco e um dos escritores selecionados pela coordenação do evento para frequentar uma oficina de crítica cinematográfica oferecida na programação:

Há alguns anos, eu tinha certo receio com filmes de terror. Gostava de um ou outro cânone, mas ainda guardava um misto de medo e preconceito com o gênero. Desde sempre, porém, um grande amigo meu, Diego Robert, foi um fã convicto do que definitivamente não me atraia no cinema. Foi justamente ele quem me emprestou o DVD de O massacre da serra elétrica, de Tobe Hooper, recomendando fortemente. [...] Achei tosco, inofensivo do ponto de vista do medo, malfeito. Isto foi há alguns anos - não saberia dizer quantos. E, caramba, como eu estava errado. [...] Por isso, devo, publicamente, desculpas a meu grande amigo: tudo o que você falava sobre esse clássico era a mais pura verdade (PEREIRA, 2013). 
O texto citado traz referências elogiosas à maneira como a trilha sonora ${ }^{2}$ original, reproduzida em seis canais na sala de projeção, sublinhou e ampliou a experiência de desconforto e medo fruída pela plateia recifense: "Tobe Hooper estreita a percepção (...) na trilha sonora desconcertante que não mantém nenhum ritmo linear, mas rasga, quebra o tom, confere um clima de tortura (ao espectador) à cena" (PEREIRA, 2013). De fato, o sound design do filme foi muito pouco analisado por críticos e pesquisadores, embora a banda sonora tenha oferecido uma contribuição importante para o resultado estético do longa-metragem de estreia de Tobe Hooper, por meio da construção meticulosa de uma sonoridade sombria, visceral e aterrorizante, conseguida com o uso de técnicas arrojadas e pouco praticadas na época, em especial a utilização de ferramentas estilísticas e princípios oriundos da musique concrète para dissolver ou apagar as fronteiras (bastante rígidas até poucos anos antes, em se tratando de produção cinematográfica) entre música e efeitos sonoros.

A musique concrète, estilo de composição chamado no Brasil de música concreta, consiste de um modo de criação de peças musicais a partir de sons e ruídos do cotidiano, tais como gritos, tiros, barulhos de animais, chão sendo varrido, portas batendo, água pingando de torneiras, tampas de garrafa sendo abertas, e assim por diante. O termo foi cunhado em 1948 pelo engenheiro eletrônico Pierre Schaeffer, que se tornou, na França, o primeiro compositor musical a usar fitas magnéticas para alterar alguns desses sons, tocando-os no sentido inverso, acelerando-os, atrasando-os ou sobrepondo-os a outros ruídos, em sinfonias musicais cujos processos experimentais vieram a influenciar a arte da composição musical para cinema, a partir da década de 1950 (PALOMBINI, 1993, p. 14). Tanto o uso de sons do cotidiano quanto as técnicas de manipulação desses sons utilizadas por Schaeffer foram ferramentas utilizadas pela equipe de sound design do filme de Tobe Hopper.

Neste texto, procuro reconstituir o processo criativo da trilha sonora de $O$ massacre da serra elétrica, com base em depoimentos dados por integrantes da equipe, bem como discutir o impacto cultural e estético desses sons, buscando destacar um aspecto pouco discutido acerca da concepção sonora do filme: a presença majoritária de aprendizes, estudantes e jovens inexperientes, na equipe responsável pela captação de som direto, pela criação de efeitos sonoros e pela concepção musical. Pretendo, com isso, demonstrar como o relativo desconhecimento das práticas tradicionais de produção e das relações entre os diferentes elos da cadeia produtiva do som no cinema, por parte dos membros da equipe, foi mais benéfico do que prejudicial ao resultado sonoro da obra, ajudando a inserir $O$ massacre da serra elétrica na galeria de títulos responsáveis por encorpar a tendência de eliminar ou apagar as fronteiras entre música e efeitos sonoros, conforme destacado por muitos pesquisadores (SERGI, 1999; KASSABIAN, 2003; CARVALHO, 2009; BURWELL, 2013; OPOLSKI, 2013; CARREIRO, BELTRÃO, 2014; GORBMAN in COSTA et al, 2016; MIRANDA, PEREIRA, 2016).

2 Entendemos a expressão "trilha sonora", neste texto, como o conjunto de todos os sons reproduzidos juntos com a imagem em movimento, o que inclui diálogos, efeitos sonoros e música. 
De fato, boa parte dos membros da equipe que trabalhou em $O$ massacre da serra elétrica desconhecia o uso avançado das ferramentas técnicas disponíveis aos sound designers dos anos 1970, tais como microfones unidirecionais shotgun e mesas de mixagem portáteis, mas era capaz de reconhecer (ainda que intuitivamente) o uso criativo dessas mesmas ferramentas, transformando um processo de tentativa e erro em um programa de aprendizado informal de um ofício. Essa trilha, como veremos, foi seguida à risca pelos membros da equipe de som.

Na época do lançamento original, em 1974, pouco se falou a respeito da sonoridade do filme de Tobe Hopper. Dois fatores podem explicar o fato de O massacre da serra elétrica ter passado, na ocasião, despercebido aos críticos. Em primeiro lugar, o próprio fato de ter sido realizado de forma independente, com orçamento limitado, por uma equipe formada por estudantes. Em segundo lugar, o longa-metragem foi mixado às pressas e em mono - ou seja, todos os sons gravados para o filme tiveram que ser espremidos em um único canal de reprodução sonora, o que tradicionalmente cria bandas sonoras densas demais, em que muitos sons gravados individualmente entram em choque com outros.

Desde então, O massacre da serra elétrica foi objeto de duas remixagens sonoras. A primeira ocorreu em 2003, e distribuiu em Dolby Stereo (três canais frontais e um surround traseiro) as trilhas de vozes, efeitos sonoros e música presentes na faixa mono original $^{3}$. A segunda, ocorrida em 2014, foi mais demorada e criteriosa. Além de restaurar e limpar digitalmente as imperfeições técnicas presentes nas gravações originais, a equipe do estúdio Post Haste Sound acrescentou uma nova trilha de ruídos de sala, para reforçar o foley original, e redistribuiu os canais sonoros estéreo organizadas em 2003 para dois formatos digitais: Dolby Digital 5.1, e Dolby Surround 7.1 (no primeiro caso, com três canais centrais e dois surround traseiros, além de um canal de baixas frequências; no segundo caso, somando-se a esses seis mais dois canais surround laterais) ${ }^{4}$.

Para este trabalho, que tem como objetivo central a reconstituição do processo criativo levado a cabo pela equipe original, procurei me ater à análise da trilha Dolby Stereo, presente no DVD lançado no Brasil pela distribuidora CineArt. Usei a trilha mono (disponível em outra versão do filme em DVD, lançado pela empresa Flashstar) apenas para efeito de comparação, pois graças à possibilidade de distribuir os elementos sonoros em quatro canais, a trilha Dolby Stereo revela, com maior precisão, o trabalho feito

3 Cada trilha contendo um grupo de elementos sonoros distintos (diálogos, efeitos e música) ganha o nome técnico de stem e é utilizada, no momento da mixagem, para simplificar o trabalho de espacialização dos sons executado pelo mixador.

4 A reestruturação da trilha de áudio do filme foi conduzida pelo sound designer Eric Dosch e contou com a supervisão do diretor Tobe Hooper, que gravou um comentário em áudio para lançamentos futuros em formatos de vídeo doméstico. Para a restauração dos trechos deteriorados do áudio original, Dosch teve acesso a todos os arquivos de voz, efeitos sonoros e música presentes na trilha mono da cópia master em 25mm do longametragem, restaurando-os individualmente e remasterizando toda a trilha ao final do processo (POST HASTE SOUND, 2014). 
em $1974^{5}$. Evitei trabalhar com a trilha mixada em Dolby Digital 5.1 porque o acréscimo de novos ruídos de sala modifica sensivelmente o trabalho realizado pela equipe original, o que inviabiliza a tarefa de reconstituir o processo criativo da época.

\section{O contexto de produção}

Para iniciar a análise da banda sonora do filme, é preciso detalhar o contexto de produção do filme de Tobe Hooper. O projeto de O massacre da serra elétrica foi concebido como uma produção independente de apenas US\$ 60 mil, custeada pela própria equipe de produção, que era formada principalmente por estudantes de cinema da universidade de Austin, no Texas (EUA), que começavam a tentar construir carreiras ligadas à área do audiovisual. Nenhum membro da equipe, com exceção de alguns atores (que já tinham experiências prévias no teatro ou na televisão local), recebeu salário para trabalhar durante as seis semanas de filmagem.

Várias pessoas que exerceram funções técnicas importantes do longa-metragem desistiram de fazer cinema após a experiência nos calorentos sets de filmagem, e mudaram para outras áreas profissionais após a realização do filme. A diretora assistente e co-montadora da produção, Sallye Richardson, foi uma dessas pessoas que nunca mais trabalhou com audiovisual. Em $O$ massacre da serra elétrica, porém, Richardson fez a edição de som, trabalhando na sincronia das trilhas de áudio com as imagens - usando uma moviola colocada na mesa de jantar da casa do diretor, Tobe Hooper - e depois supervisionou a mixagem sonora, realizada por técnicos do estúdio de gravações Todd-AO, em Los Angeles (EUA). Uma descrição minuciosa das etapas de produção e pós-produção está disponível no livro O massacre da serra elétrica - Arquivos sangrentos, escrito por Stefan Jaworzyn.

A equipe de captação do som direto era formada por apenas duas pessoas, ambas sem experiência na área: Ted Nicolaou e Wayne Bell. Como não conheciam os procedimentos técnicos desse tipo de trabalho, os dois simplesmente dividiram as tarefas por afinidade com as exigências da rotina diária. Nicolaou (que mais tarde exerceria a função de técnico de som direto em dois longas, antes de ocupar outras funções até se tornar diretor de filmes de baixo orçamento, no final dos anos 1980) preferia ficar à distância, sentado, e por isso ficou encarregado de operar o gravador Nagra, enquanto Bell (que depois trabalhou na pós-produção criando a música e os ruídos de sala ${ }^{6}$, junto com o próprio Tobe Hooper) optou por exercer a função de microfonista. Os dois tinham uma mesa de mixagem colocada sobre um carro de golfe, mas como não sabiam operar o equipamento, somente

5 É importante lembrar que o formato Dolby Stereo distribui em quatro canais, por meio de um complicado trabalho de processamento digital de dados sonoros, as informações disponíveis em dois canais estéreo comuns (ou seja, esquerdo e direito). As informações sonoras presentes no canal central consistem da soma desses dois canais decrescida de alguns decibéis, enquanto os sons endereçados ao canal surround reproduzem a mesma soma alterada eletronicamente.

6 Em inglês, chamados de foley, e que consistem na produção de todos os ruídos produzidos pelo contato do corpo humano com o ambiente, como passos e o farfalhar de roupas. 
a usaram na sequência gravada dentro do carro. Nas demais cenas, foi usado apenas um microfone shotgun, plugado diretamente no Nagra:

Microfonar com o boom é mais próximo do balé porque seu parceiro de dança é o ator; os atores e a cena que eles estão criando bem na sua frente: ela se move para cá, para lá, fica meio alta aqui, calminha ali e muda a cada performance. Você sai com a sensação de ser a pessoa mais íntima do filme que está acontecendo na sua frente - chega primeiro aos seus ouvidos (BELL in JAWORZYN, 2013, p. 71).

Mesmo depois da remixagem feita em 2003, quando todos os sons foram restaurados e limpos digitalmente, a falta de experiência da dupla pode ser percebida por espectadores atentos. Na curta sequência de diálogos que ocorre dentro do cemitério, logo após os créditos de abertura, a perda do eixo do microfone é audível em alguns momentos, quando os atores giram a cabeça enquanto falam. Em outros momentos do filme, que tiveram que ser dublados, a sincronia labial fica comprometida, graças à falta de tempo e de recursos técnicos.

Nesse ponto, é preciso observar a astúcia de Tobe Hooper, diretor do filme. Sabedor das limitações criativas, técnicas e orçamentárias da equipe, ele concebeu um roteiro no qual a trama ficava em segundo plano, em detrimento da atmosfera decrépita. Em O massacre da serra elétrica, importam pouco as conexões causais entre ações dramáticas. O impacto visceral na plateia - em bom português, deixar o espectador com os nervos em frangalhos, assustado e sem saber o que esperar da próxima cena - era o objetivo principal. Por isso, Hooper escreveu um roteiro com poucos diálogos: o filme tem menos de seis falas por minuto, a maioria concentrada em duas sequências: a já descrita cena dentro do carro e o macabro jantar do terceiro ato com os membros da família canibal que protagoniza o filme.

Este baixo número de diálogos não apenas rema contra a tendência de filmes muito expositivos que encontramos em Hollywood, onde os longas-metragens costumam ter entre 10 e 12 linhas de diálogo por minuto. Hooper, dessa forma, alinha O massacre da serra elétrica ao estilo de cinema nomeado por Michel Chion como lacônico (CHION, 2009, p. 73), e que conta com diretores como Jacques Tati, Robert Bresson e Sergio Leone entre seus representantes - todos cineastas conceituados, com relação ao tratamento dado ao som. Ao insistir no cinema lacônico, Hooper não apenas minimizava as limitações da equipe, mas também abria espaço para dar destaque à criação sonora na área da pós-produção, acentuando o caráter afetivo da música e dos efeitos sonoros.

Essa decisão criativa se mostraria acertada, mas o caráter inexperiente visto na equipe de captação do som direto se repetiu na fase da pós-produção. Em uma época anterior à criação do termo sound design, em que havia menos de dez profissionais em atuação no foley dentro dos Estados Unidos (BUHLER; NEUMEYER; DEEMER, 2010, p. 377) e a música orquestral de sabor neorromântico dominava a produção cinematográfica, apenas três 
pessoas trabalharam na pós-produção de O massacre da serra elétrica. Sallye Richardson, que montou o filme, realizou também a edição de som, em que teve a incumbência de sincronizar as 25 faixas de áudio originais de voz, música e efeitos sonoros usadas pela equipe da produtora Todd-AO para produzir a mixagem mono original; Wayne Bell e o próprio diretor, Tobe Hooper, criaram a música e o foley ao mesmo tempo, trabalhando em dupla, numa abordagem criativa completamente original e distante da metodologia utilizada corriqueiramente por profissionais de pós-produção sonora, em que diferentes equipes (quase sempre sem conversar entre si) criam, paralelamente, ruídos de sala, efeitos sonoros e música. Diante da documentação farta do processo de pós-produção (JAWORZYN, 2013), é possível afirmar que o som assustador do longa-metragem nasceu do método caótico - que poderia ser descrito mais precisamente como falta de método - de trabalho dessa dupla.

De acordo com as memórias compiladas por Stefan Jaworzyn (2013), toda a pós-produção de $O$ massacre da serra elétrica foi realizada na casa de Tobe Hooper. Como o orçamento havia acabado e a produção não tinha dinheiro para alugar um estúdio de edição, Hooper conseguiu uma moviola Steenbeck emprestada e instalou na sala de jantar, enquanto Wayne Bell reuniu uma série de instrumentos exóticos de percussão, acrescentou objetos cotidianos (ossos de animais, cenouras, pepinos, moedas de prata, sinos, apitos, pregos e pequenas peças de metal e madeira), violinos e baixos quebrados, além de um sintetizador, e levou tudo para um quarto da mesma casa. Todas as noites, durante seis semanas, o diretor do filme ia da sala ao quarto e vice-versa, trabalhando na montagem e no som ao mesmo tempo. As ideias nascidas em um cômodo alimentavam o trabalho no outro, e vice-versa.

\footnotetext{
Às vezes, Tobe estava lá cortando uma cena e pensando sobre ela (...) em termos de concepção, no que diz respeito a direção musical de verdade, às vezes nós fazíamos "gelo", ou às vezes "ossos" ou "perseguição", "quente", "frio" ou "suspense". A música de Massacre era apenas nós dois tocando juntos - eu inventava algumas coisas para mostrar a ele, mas basicamente nós levávamos um som no improviso e víamos até onde aquelas coisas iam (BELL in JAWORZYN, 2013, p. 91).
}

Como a montadora do filme fazia a edição de som na sala de estar ao lado, no mesmo apartamento, a configuração de trabalho permitiu experiências que normalmente, em um filme normal, não seriam possíveis. É importante lembrar como funciona a cadeia produtiva do cinema, em termos profissionais: na pós-produção, dois grupos distintos de pessoas trabalham em simultâneo, o primeiro organizando e tratando as imagens, e o segundo fazendo o mesmo com o som. Esses grupos podem se subdividir em inúmeras equipes menores, e a comunicação entre esses agrupamentos de profissionais é pouco comum. Nesse sentido, o pequeno número de pessoas e o fato de dividirem o local de trabalho fez com que som e imagem fossem pensados como uma coisa única, indivisível. 
Em outras palavras, a abordagem improvisada gerou um pensamento criativo integrado entre som e imagem bastante raro no cinema. É por isso que O massacre da serra elétrica produziu uma espécie de triunfo de aprendizes: foi exatamente esse caráter despretensioso que permitiu ao som do filme transcender a rigidez na separação do processo produtivo profissional em categorias pouco integradas (diálogos, música, efeitos sonoros, foley, imagem), produzindo um todo coeso e fluido que traz cenas assustadoras.

Além disso, como os ruídos de sala foram produzidos neste ambiente caseiro, Hooper e Bell não puderem trabalhar minuciosamente na sincronia entre os ruídos e os movimentos dos corpos dos personagens. Por isso, o foley foi gravado aleatoriamente, sem o auxílio das imagens editadas, e só depois sincronizado por Sallye Richardson. É por esta razão que predominam, nos ambientes e efeitos sonoros, os sons fora de quadro, que não possuem pontos de síncrese (CHION, 1994, p. 63).

$\mathrm{Na}$ faixa mono original, a inexperiência da equipe - bem como o resultado incomum - pode ser percebido por espectadores atentos. Por exemplo, a sequência dos créditos de abertura, que chama a atenção para o som, é um exemplo dessa fluidez. O filme abre com uma série de ruídos assustadores que ecoam sob a tela negra pontuada apenas ocasionalmente por planos-detalhes assustadores de uma caveira - a estratégia de usar som ambiente sob uma tela negra é uma técnica tradicional usada por sound designers para aguçar a curiosidade e a escuta do espectador, direcionando sua atenção para a banda sonora.

Também não há sincronia entre os sons e elementos da imagem. A assincronia, usada como ferramenta estilística ao longo de todo o filme, costuma provocar curiosidade no espectador, levando-o a dirigir mais atenção do que o normal aos sons. Em um filme de horror, a assincronia é ainda mais importante: deixa a plateia tensa e alerta, lidando sempre com a suspeita de que os sons acusmáticos - ou seja, aqueles cuja origem não pode ser vista, como explica Michel Chion (1994, p. 61) - signifiquem ameaça e violência eminente. $\mathrm{Na}$ abertura de $\mathrm{O}$ massacre da serra elétrica, bem como em várias outras cenas, a equipe de sound design associou as técnicas oriundas da musique concrète com a condição acusmática, sublinhando de modo potente a tensão gerada pelos sons de textura sombria e desconhecida.

Alguns dos ruídos presentes na sequência de abertura lembram uma faca ou foice partindo carne e ossos, enquanto a respiração pesada de um indivíduo que nunca é visto sugere excitação e violência. Rangidos e ataques ocasionais de um címbalo, e toda uma sorte de pequenos barulhos metálicos ameaçadores, cuja origem também não aparece, ampliam a tensão. Um oscilador eletrônico providencia um zumbido que preenche todo o espectro de frequências, nos momentos em que as imagens do esqueleto surgem na tela.

À luz da descrição que Wayne Bell (JAWORZYN, 2013, p. 90) faz do modo como esses sons foram produzidos, a sequência exemplifica a dissolução das fronteiras entre música e efeitos sonoros. Segundo o músico, o resultado final foi conseguindo mixando-se dois conjuntos de sons produzidos separadamente. Há uma série de zumbidos produzidos 
com a ajuda de um teclado eletrônico - os sons musicais foram processados em diferentes velocidades de reprodução, seguindo uma das técnicas mais tradicionais das experiências em musique concrète popularizadas por Pierre Schaeffer (PALOMBINI, 1993), e ganharam o acréscimo de um reverb pesado. Para conseguir essa reverberação, Bell e Tobe Hooper gravaram tudo com microfones de contato colocados na ponta de um tubo de papelão, enquanto a fonte dos sons ficava na outra ponta. Foi gravada, também, uma sessão de foley, na qual Tobe Hooper partia ossos, pedaços de carne e vegetais com um facão. A união de música e efeitos gera uma massa sonora inquietante e sombria, algo realçado pela escuridão da tela negra - uma abertura perfeita para um filme desorientador, que nunca deixa o espectador intuir para onde está indo.

A tática de unir sons percussivos e ruídos do cotidiano produzidos como foley a notas musicais eletronicamente modificadas - uma prática tradicional da musique concrète foi repetida ao longo do filme inteiro. Por causa da falta de padrões rítmicos, pela textura rascante e agressiva, e pela ausência de correspondência visual com elementos da imagem, a trilha sonora ajuda a realçar a experiência de medo e desorientação do espectador, que é mantido num estado de alerta constante, por não saber a natureza exata do que ouve e por não conseguir localizar diegeticamente a origem desses ruídos. É elucidativo perceber, também, a intencionalidade dos próprios criadores de sons quanto ao apagamento da fronteira até então rígida entre música e efeitos sonoros, já que eles faziam questão de nunca agrupar os arquivos sonoros seguindo recursos musicais como ritmo, harmonia ou melodia (JAWORZYN, 2013, p. 93).

Os sons ouvidos durante o jantar da família canibal no terceiro ato, em que Leatherface (Gunnar Hansen) e os parentes molestam a aterrorizada protagonista Sally (Marylin Burns), constituem um exemplo da eficiência da estratégia criativa. A banda sonora deixa realmente os nervos à flor da pele: zumbidos, apitos e chiados invadem o ambiente de todos os lados - a remixagem em Dolby Stereo feita em 2003, em que esses sons foram distribuídos entre os canais disponíveis, contribui bastante para acentuar ainda mais esse efeito afetivo - enquanto os canibais falam, grunhem e sorriem de modo sinistro, e a moça amarrada e amordaçada geme e respira pesadamente em completo terror.

Todas essas cenas funcionam com eficiência no contexto narrativo do filme, mas talvez o exemplo mais assustador de sound design esteja na longa sequência em que Leatherface aparece pela primeira vez, matando um casal de jovens, um de cada vez. Sem nenhum diálogo, com exceção de algumas frases gritadas ocasionalmente pelos personagens, a sequência inteira é sublinhada pelo som ritmado, monótono e insistente de um gerador elétrico (visto no quintal de relance, em um plano fechado exibido logo no início da sequência) responsável por fornecer energia à casa semiabandonada.

Notas de piano desaceleradas eletronicamente (e com as frequências mais graves realçadas) pontuam a cena arritmicamente, quando os personagens entram na casa, um a um, e se tornam mais vulneráveis. A decrepitude das imagens - penas e esqueletos 
de animais espalhados por todo lado - é amplificada pelos sons exóticos: o cacarejar de uma galinha (presa ao teto dentro de uma gaiola) e uma série de grunhidos que não nos permitem identificar a fonte agregam tensão e imprevisibilidade ao momento, antes que duas aparições tão inesperadas quanto rápidas de Leatherface, matando os jovens em dois momentos separados, adicionem à trilha sonora gritos de pavor - a assinatura sonora mais reconhecível do filme, tanto quanto o zumbido agressivo da serra elétrica do título.

Ao final da cena, quando os jovens estão mortos e Leatherface trancou-se de novo no cômodo fechado por uma porta corrediça de ferro, a casa volta a ficar em silêncio. A dinâmica entre momentos silenciosos e ataques repentinos de ruído de grande amplitude também ajuda a realçar o horror. Tobe Hooper inclui ainda, no final da sequência, um close fechado de um moinho de vento enferrujado, cujo rangido ritmado prepara a transição para a próxima cena. Esse plano pode ser perfeitamente visto como uma homenagem direta do cineasta norte-americano à sequência de abertura de Era uma vez no Oeste (C'era uma volta il West, Sergio Leone, 1968), outra célebre cena sem diálogos em que os ruídos são utilizados como música, e que parece ter sido a fonte principal de influência para o sound design do duplo assassinato.

\section{Considerações finais}

As sequências descritas e analisadas sintetizam algumas das virtudes do som de O massacre da serra elétrica. Elas incorporam o reforço ousado à tendência de apagamento das fronteiras entre música e efeitos sonoros, na época adotada de forma bastante tímida e atualmente bastante comum nas mais variadas filmografias nacionais, em filmes nos quais tem sido cada vez mais difícil identificar "as diferenças entre ruído, som e música" (KASSABIAN, 2003, p. 91).

Antes dos anos 1970, eram muito escassos os filmes norte-americanos que investiram nesse tipo de representação sonora. Os trabalhos inventivos de Sergio Leone, Jean-Luc Godard, Jacques Tati e Robert Bresson ainda não haviam atingido a popularidade que teriam alguns anos mais tarde, e as técnicas inovadoras da musique concrète de Pierre Schaeffer não era conhecida para além do círculo dos artistas de vanguarda.

Visto atualmente, com a devida perspectiva histórica, o longa de Tobe Hooper parece ter integrado o primeiro ciclo de filmes feitos nos Estados Unidos a ampliar a importância estética dada a ruídos e efeitos sonoros, uma tendência notada por Gianluca Sergi $(2005)^{7}$. O pesquisador observa que a valorização dos ruídos como categoria de sons capazes de ajudar criativamente a narrar o enredo ocorreu a partir da ascensão da primeira geração de profissionais exclusivamente dedicada à prática ainda incipiente do sound design: Walter Murch, Ben Burtt, Alan Splet, Gary Rydstrom e Randy Thom, cada um aplicando influências pessoais (música concreta, animações dos anos 1940 e 1950, rádio) em direção a um objetivo comum.

7 Embora concebido numa escala orçamentária e logística muito maior, e por meio de um modo de produção mais profissional, um trabalho que guarda semelhanças com O Massacre das Serra Elétrica talvez seja o primeiro Guerra nas Estrelas (Star Wars, George Lucas, 1977), no qual o sound designer Ben Burtt, recém-saído da universidade, também trabalhou de forma experimental para construir efeitos sonoros, como o famoso zumbido do sabre de luz. 
Este objetivo comum, na verdade, parece ter sido impulsionado ainda por um fator tecnológico: a consolidação do primeiro sistema estereofônico a ser adotado massivamente pela indústria do audiovisual - o sistema Dolby Stereo, que chegou ao mercado em 1975 e tornou-se um sucesso mundial dois anos depois, no rastro do fenômeno Guerra nas Estrelas. A adoção do Dolby Stereo, graças à presença de canais surround, possibilitou aos sound designers a chance de iniciar a tendência de usar o som para fazer o espectador imergir no universo diegético, cercando-o por todos os lados. Essa tendência só seria efetivamente consolidada com a criação de sistemas digitais de reprodução sonora, na década de 1990, mas o Dolby Stereo impulsionou, de forma definitiva, o sound design de filmes em direção ao desenvolvimento de estratégias de mixagem que proporcionam um senso de imersão aprofundado do espectador (KERINS, 2010, p. 190).

Como explicar, então, a ausência de $O$ massacre da serra elétrica na lista de filmes dos anos 1970 que ajudaram a valorizar o ruído como categoria estética importante para a narração cinematográfica ${ }^{8}$ ? Além da ausência quase completa de marketing na época do lançamento nos cinemas, é provável que a mixagem mono da banda sonora original tenha feito passar despercebido o trabalho meticuloso de produção de efeitos sonoros, música e foley. Como o Dolby Stereo só apareceria um ano depois do lançamento do filme, os diferentes tipos de sons foram comprimidos em um único canal de áudio, dando pouco espaço ao ouvinte para sentir-se evolvido por aquele conjunto exótico de sons macabros.

Esse problema foi devidamente corrigido nas remixagens subsequentes que vieram, todas investindo fortemente na potência da imersão do espectador dentro do mundo ficcional habitado pelos personagens. Tobe Hooper, de fato, admite que fazer o espectador imergir ainda mais dentro da ação dramática foi o objetivo central do trabalho de remixagem feito em 2014 (COLLIS, 2014). Por isso, não é coincidência que muitas críticas ao filme escritas a partir de meados dos anos 2000 (ou seja, depois do primeiro remix feito no áudio do longa) tenham passado a citar como pontos altos do filme elementos da trilha sonora, algo pouco lembrado nos anos 1970 e 1980. Um exemplo:

[O som em] O massacre da serra elétrica foi marcado com a mesma mistura de pragmatismo, crueza e sensibilidade experimental que impregna a sua fotografia, edição e, particularmente, direção de arte. As suas qualidades fantasmagóricas são muito admiradas, mas pouco se tem escrito sobre a sua construção formal, além de anedotas sobre alguns dos itens domésticos de cozinha usados como fontes de foley. Esta prática é citada como exemplo da atitude punk de Hooper; na verdade, ela também demonstra uma compreensão da música avant garde do século XX, com o qual o diretor é aparentemente familiar. O design de som pode ter sido amador, mas o entrelaçamento inteligente de som diegético e não diegético no filme, que atinge o seu ápice com o zumbido do instrumento doméstico de notório poder do título fundido com o filtro de baixa frequência

8 Filmes habitualmente citados como inovadores em sound design incluem, nos anos 1970, títulos como A conversação (The conversation, Francis Ford Coppola, 1974), Apocalypse now (Francis Ford Coppola) e o já citado Guerra nas Estrelas. 
sinistro de um sintetizador analógico, mas na verdade ocorre por toda parte, e resulta em uma experiência sonora que é ainda mais notável para a inexperiência de seus compositores. (MORGAN, 2009).

Como Frances Morgan enfatiza no texto, a mistura indistinta de música e ruídos (que ele menciona como entrelace de sons diegéticos e não diegéticos) posiciona $O$ massacre da serra elétrica entre os pioneiros na utilização da música concreta e experimental, misturando notas longas, desafinadas incômodas e fantasmagóricas a ruídos do cotidiano, evitando o uso de melodia, harmonia ou ritmo estáveis. Esse tipo de música se tornou popular em filmes de horror norte-americanos, a partir dos anos 1990, por uma série de razões - sobretudo porque possui forte característica de imprevisibilidade, permitindo aos cineastas que a usem de modo a adicionar tensão e suspense.

Neste ensaio, procuramos enumerar e analisar características estéticas inovadoras de $O$ massacre da serra elétrica. Parece-nos perceptível que a maior parte delas são decorrentes, direta ou indiretamente, do caráter improvisado e inexperiente da equipe criativa do longa-metragem. Se o filme houvesse sido produzido da forma tradicional, dentro de um grande estúdio, provavelmente soaria muito diferente - e talvez não tão interessante. O caráter de ousadia irreverente, quase displicente, que permeia a concepção criativa de sua trilha sonora é um raro triunfo de aprendizes no cinema, e uma prova de que nem sempre os melhores filmes são aqueles que valorizam a perfeição técnica.

Rodrigo Carreiro é professor do Programa de Pós-graduação em Comunicação e do Bacharelado em Cinema e Audiovisual da UFPE. É doutor em Comunicação pela UFPE e bacharel em Jornalismo pela Universidade Católica de Pernambuco.

rcarreiro@gmail.com

\section{Referências}

BUHLER, J.; NEUMEYER, D.; DEEMER, R. Hearing the movies: music and sound in film history. New York: Oxford University Press, 2010.

BURWELL, C. No country for old music. In: RICHARDSON, J.; GORBMAN, C.; VERNALLIS, C. (Org.). The Oxford handbook of new audiovisual esthetics New York: Oxford University Press, 2013. p. 168-170.

CARVALHO, M. Anos 1070: o desenlace da polifonia tropical e a marginália na música de cinema. In: LUNA, R. (Org.). Nas trilhas do cinema brasileiro. Rio de Janeiro: Tela Brasilis Edições, 2009. p. 84-95.

CHION, M. Audiovision: sound on screen. New York: Columbia University Press, 1994. 
Film, a sound art. New York: Columbia University Press, 2009.

COLLIS, C. Tobe Hooper talks about the new, restored version of The Texas chain saw massacre. Entertainment Weekly, 6 de março de 2014. Disponível em: http://www.ew.com/article/2014/03/06/ sxsw-texas-chain-saw-massacre-tobe-hooper. Acesso em: 30 maio 2017.

COSTA, F. M.; CARREIRO, R.; MIRANDA, S. R. Uma entrevista com Claudia Gorbman. Rebeca Revista Brasileira de Estudos de Cinema e Audiovisual, v. 5, n. 1. São Paulo: SOCINE, p. 170-188, 2016.

JAWORZYN, S. O massacre da serra elétrica: arquivos sangrentos. Rio de Janeiro: Darkside Books, 2013.

KASSABIAN, A. The sound of a new film form. In: INGLIS, I. (Org.). Popular music and film. London: Wallflower Press, 2003. p. 91-101.

KERINS, M. Beyond Dolby (Digital): cinema in the digital sound age. Bloomington: Indiana University Press, 2010.

MORGAN, F. The Texas Chain Saw Massacre. Electric sheep: a deviant view of cinema [magazine], v. 9, inverno de 2009. Disponível em: http://www.electricsheepmagazine.co.uk/reviews/2009/12/01/ texas-chain-saw-massacre/. Acesso em: 30 maio 2017.

NEWMAN, K. Nightmare movies: Horror on screen since the 1960s. London: Bloomsbury Publishing Co., 2011.

OPOLSKI, D. Introdução ao desenho de som: uma sistematização aplicada na análise do longametragem Ensaio Sobre a Cegueira. João Pessoa: Editora da UFPB, 2013.

PALOMBINI, C. Pierre Schaeffer: from research into noises to experimental music. Computer Music Journal, n. 17, v. 3. Cambridge: Massachusetts Institute of Technology Press, p. 14-19, 1993.

PEREIRA, J. O massacre da serra elétrica, de Tobe Hooper. VII Janela Internacional de Cinema do Recife [blog], 25 de outubro de 2014. Disponível em: http://janela.art.br/index.php/criticas/ vii-janela-internacional-de-cinema-do-recife-o-massacre-da-serra-eletrica-de-tobe-hooper/. Acesso em: 29 mai. 2017.

PEREIRA, K.; MIRANDA, S. R. Tão longe é aqui e a música dos ruídos: Aproximações teóricas sobre aspectos do som no cinema contemporâneo. Rebeca - Revista Brasileira de Estudos de Cinema e Audiovisual, v. 5, n. 1. São Paulo: SOCINE, p. 170-188, 2016.

SERGI, G. In defense of vulgarity. Scope [magazine], v. 5, n. 1. Nottingham, junho de 2006. Disponível em: http://www.nottingham.ac.uk/scope/documents/2006/june-2006/sergi.pdf. Acesso em: $1^{\circ}$ jun. 2017.

Artigo recebido em 1 de junho e aprovado em 11 de agosto de 2017. 